\title{
Out-of-hospital open-chest cardiopulmonary resuscitation after cardiac arrest in cases of blunt chest or abdominal trauma: A consecutive series of 40 cases
}

\author{
Wen-Hai Liu*, Xu-Dong Wang, Lian-Fu Wang, Wei Liu, Ting Liu, Jia-Wei Liu, Hai-Bing Zhang and Chun-Yi Chiang \\ Department of Emergency, Aerospace Center Hospital (Peking University Aerospace School of Clinical Medicine), 100049 Beijing, China
}

\begin{abstract}
Background and Objective: Open-chest cardiopulmonary resuscitation (OCCCPR) may be the only method of increasing the survival rate as well as the cardiorespiratory circulation of blunt chest or abdominal trauma patients undergoing cardiac arrest, however, it has always been a difficult challenge for medical staff to carry out on-sight OCCPR because it requires high level of expertise. Unfortunately, professionally qualified individuals are scarce and rarely participate in Outof-Hospital resuscitations. The aim of this study was to determine the effectiveness of establishing on-sight or early OCCPR and the probability of increasing the success rate of resuscitation in blunt chest or abdominal trauma patients undergoing cardiac arrest.

Methods: In a retrospective study, a total of 40 chest/abdominal trauma cardiac arrest cases were collected from $2006 \sim 2015$. Patients with blunt trauma and underwent cardiac arrest until the arrival of EMT performing uninterrupted open-chest CPR (OCCPR) of less than 10 minutes or closed-chest CPR of less than 15 minutes were included in this study. The main cause of death was chest/abdominal trauma and on-sight OCCPR were performed by trauma surgeons. According to the recovery, the patients were assigned to three groups: Group 0 Mortality, Group 1 Re-established Circulation and Group 2 Recovery.

Results: Of the 40 cases, 6 patients (15.00\%) had re-established circulation and was discharged after rehab, 15 patients (37.50\%) had re-established circulation but died of other complications, 19 patients $(47.50 \%)$ was not resuscitated. The average age of the surviving patients was $32.67 \pm 17.24$ years old, the average age for patients who had re-established circulation was $44.40 \pm 15.75$ years old. In the mortality group, the average age is $35.32 \pm 14.89$ years old. When compared, the difference in age among the three groups of patients shows no statistical significance $(P=0.164)$; the New Injury Severity Score (NISS) of group 0 is $56.00 \pm 5.62$, and group 1 is $56.00 \pm 3.35$ and group 2 is $64.21 \pm 1.80$, the three groups showed no statistical significance in the severity of trauma $(P=0.072)$. The amount of time taken from distress call to performing OCCPR in group 2 was $14.50 \pm 9.83$ minutes, group 1 was $19.73 \pm 6.02$ minutes, group 0 was $26.58 \pm 12.18$ minutes, which among the three groups showed statistical significance $(P=0.025)$, further comparison also indicates that the difference in time between group 2 and group 0 had statistical significance $(P=0.014)$.
\end{abstract}

Conclusion: On-sight or early performance of OCCPR is viable and is encouraged to be utilized more in trauma centers. It is proven that early performance of OCCPR can increase the survival rate of those patients with chest and/or abdominal trauma undergoing cardiac arrest.

\section{Introduction}

When performing Closed Chest Cardiopulmonary Resuscitation, CCCPR on Patients with blunt-chest and abdominal trauma resulting in cardiac arrest, their survival rate is less than $1 \%$ [1]. Individuals with blunt chest and abdominal trauma may have injured chest abdominal pump, hence affecting the hemodynamics when CCCPR is applied, not enough blood is circulated to the brain and myocardium [2,3]. This condition may be further aggravated causing complication such as hematopneumothorax, rupture of the heart or pericardial tamponade, resulting in long-term low recovery rate.

The difference between Open Chest Cardiopulmonary Resuscitation and Close Chest Cardiopulmonary Resuscitation is the method of compression: OCCPR directly compresses the ventricles after opening the pericardium. It does not rely on the completeness of the chest walls or the intrathoracic pressure changes, therefore obtaining a more effective stroke volume. More importantly, while providing effective circulatory assistance, OCCPR can correct the main cause of cardiac arrest as early as possible [4]. It is dismay for us that the level of expertise required for OCCPR is high and not implementing OCCPR in a timely manner lead to ischemia and lowered recovery rate.
Therefore across 10 year study, we suggest that the implementation of OCCPR as early as possible on individuals with cardiac arrest caused by blunt trauma may be the key factor in increasing the survival rate of these individuals. Based on this, in the retrospective case study, we explore early or on-sight performance of cardiac resuscitation and its significance effect on the success rate of resuscitation.

\section{General information and methods}

\section{General information}

The Department of Emergency in Aerospace Center Hospital was established in 1984. Open-Chest Cardio-pulmonary Resuscitation

Correspondence to: Wen-Hai Liu, Department of Emergency, Aerospace Center Hospital (Peking University Aerospace School of Clinical Medicine), 100049 Beijing, China, Tel: +86-10-59971204; E-mail: wh717@sina.com

Key words: early ER, OCCPR, thoracic abdominal trauma, cardiac arrest

Received: February 06, 2017; Accepted: February 28, 2017; Published: March 03, 2017 

40 cases

team was established in 2001, the individual responsible for the group has more than 20 years of cardiothoracic surgical experience, which included 4 doctors and 4 subgroups with a total of 16 nurses, All personnel mentioned have a 24 hour rotation and stand-by work hours, once an operation is available, 2 doctors will arrive at the ER or the on-sight location ( $5 \mathrm{Km}$ radius from the hospital) within 5 minutes. Beijing First-Aid Institute Western Branch is located within the hospital grounds, they are able to provide real-time information on any possible distress calls, allowing us the opportunity to perform Open-chest cardio-pulmonary resuscitation when needed.

\section{Subject of study}

The study was done using case review. From January 2006 to January 2015, we had continuously collected 40 cases from Emergency Department in Aerospace center hospital mainly of thoracic or abdominal trauma that resulted in cardiac arrest, other criteria included the time taken to make the distress call and patient's age between 8-70 years old were also considered. Of the 40 cases, 31 were male, and 9 were female, which range from 9-69 years old with an average age of $38.33 \pm 15.90$ years old; 15 cases occurred on the ambulance, 25 cases were carried out in the surgery room in ER; there were 11 cases of thoracic puncture (not including the heart), 29 cases were closed chest/abdominal trauma. Of the cases, 6 cases had re-established circulation and made complete recovery after rehabilitation $(15.00 \%)$, 15 cases had re-established circulation but resulted in death from other complications (37.50\%), 19 cases had unsuccessful cardiac resuscitation (47.50\%). The specific etiology, NISS and time distribution from distress call to OCCPR is listed in Table 1.

\section{Clinical basis and legal basis}

All surgical indications and methods for OCCPR were done according to the "2005 American Heart Association Cardiopulmonary Resuscitation and Emergency Cardiovascular Care Guidelines" (2010 Guidelines remained the same as 2005). OCCPR was done only after consent was signed by either immediate family members or close relatives. According to the provision of Article 56 of The Liability Law of the People's Republic of China, when case of life-threatening situation and consent was not obtained, the medical institution has the authority to approve and implement OCCPR to the patient in need.

\section{Indication for OCCPR}

Any individual with a past history of chest-abdominal trauma, short term unconsciousness, respiratory arrest or ineffective breathing can be correctly diagnosed using TCPA and indicated for OCCPR. To those who under the suspicion of severe internal chest-abdominal trauma that may lead to cardiac arrest (such as pericardial tamponade, rupture of the heart and major vessels, tension pneumothorax etc.) can undergo stage I surgery correcting the cause of cardiac arrest, at the same time increases the success rate and chances of stage II surgery; these are the absolute indications for OCCPR.

\section{Surgical methods}

The two groups utilized tracheal intubation and ventilators. After disinfecting the surgical area with iodine twice, then an incision was made on the left $4^{\text {th }}$ intercostal space anterolaterally, if a right side penetration trauma is evident. We use right side open chest access, or both sides can still be implemented, usually a center open chest access was not recommended. A chest retractor was put in place, an vertical incision made to the pericardium; compression method: single-hand compression with a rate of $70 \mathrm{bpm}$, a chest drainage is put in place at the end of the operation, if cardiac reconstruction is not done, pericardium drainage is usually not used, but a chest drainage was routinely put in place.

\section{Transfer and close-chest timing}

Tracheal intubation and ventilator were used to control breathing; which has an effective inhibition on fatal bleeding; established CVP or effective venous pathway. Once on sight effective cardiac compression has started, the patient can be transferred, once OCCPR $>20$ minutes and was stable, the chest can be closed [5].

\section{Defibrillation}

The early group used the American ZOLL two-way wave defibrillator, setting the voltage to $10 \mathrm{~W} / \mathrm{S}$ on the first defibrillation, $15 \mathrm{~W} / \mathrm{S}$ on the second, and $20 \mathrm{~W} / \mathrm{S}$ on the third, direct defibrillation over $30 \mathrm{~W} / \mathrm{S}$ is not recommended [5].

\section{Standard of effectiveness}

Recovered individuals: Complete recovery with no evidences of sequelae, the ability to carry out daily tasks is close to a healthy individual. Self-circulation re-established Individuals: can maintain effective heart stroke and blood pressure without relying on special medical equipment.

Unsuccessful resuscitation: Time implantation of OCCPR from start to finish is no less than 30 minutes; within 24 hours after reestablishing pulse, a second resuscitation is needed.

Implementation of OCCPR: Time from commencement of OCCPR to start of compression.

Cardiac arrest period: Time from when 120 receives the distress call to the start of OCCPR.

\section{Statistical analysis}

SPSS17.0 Application Software Package was used for statistical analysis, data $x \pm s$ uses Kolmogorov-Smirnov Normality Test for normal distribution, and data with homogeneity of variance uses the variance analysis, skewed distribution uses Mann-Whitney $U$ test for analysis. All data were tested by Two-Tailed test, and the difference showed statistical significance with $p<0.05$.

\section{Results}

\section{Age comparison of in 3 groups}

The Study included 40 cases, 31 cases were male, 9 cases were female, an average age was $38.33 \pm 15.90$ years old; 6 out of 40 cases made complete recovery, 15 cases had reestablished circulation but died of complication, 19 cases (Average age $35.32 \pm 14.89 \mathrm{yr}$ ) had unsuccessful resuscitation. The age difference among the 3 groups shows no statistical significance $(\mathrm{P}=0.164)$, seen in Table 2 .

\section{New injury severity score, NISS comparison of the three groups}

NISS of the survivor group was $56.00 \pm 5.62$ points, the reestablished Circulation Mortality group was $56.00 \pm 3.35$ points, the non-survivor group was $64.21 \pm 1.80$ points, which showed no statistical significance $(P=0.072)$, as seen in Table 3 .

\section{Time from admission to OCCPR}

The time elapsed from admission to OCCPR for the complete 
Liu WH (2017) Out-of-hospital open-chest cardiopulmonary resuscitation after cardiac arrest in cases of blunt chest or abdominal trauma: A consecutive series of 40 cases

Table 1. List of Implementation of OCCPR in Patients with Chest and Abdominal Trauma. Group: 0 : Unable to establish circulation during cardiac resuscitation, 1: Established circulation, died because of complication during hospitalization, 2 : Established circulation and complete recovery during hospitalization.

\begin{tabular}{|c|c|c|c|c|c|c|c|c|}
\hline$\stackrel{\vec{E}}{\vec{E}}$ & $\frac{\grave{d}}{\bar{E}}$ & $\stackrel{8}{4}$ & ڤે & Indication & Confirmed Leading Diagnosis & $\begin{array}{c}\text { Open/Close } \\
\text { Trauma }\end{array}$ & NISS & $\begin{array}{c}\text { Time from } \\
\text { CA to } \\
\text { OCCPR }\end{array}$ \\
\hline 1 & M & 26 & 0 & R.Chest Sharp Trauma & $\begin{array}{l}\text { Lung Rupture, Hematopneumothorax, Multiple Chest Wall Penetration } \\
\text { Injury }\end{array}$ & Open & 50 & 35 \\
\hline 2 & $\mathrm{~F}$ & 31 & 2 & L.Chest Sharp Trauma & Cardiac Rupture, Cardiac Tamponade, Hematopneumothorax & Open & 59 & 3 \\
\hline 3 & M & 33 & 0 & Traffic Accident & Hematopneumothorax, Hepatorrhexis, Spleen Rupture & Close & 64 & 45 \\
\hline 4 & M & 19 & 0 & Falling Polytrauma & $\begin{array}{l}\text { Hematopneumothorax, Spleen Rupture, Basal Fracture with Intracranial } \\
\text { Injury }\end{array}$ & Close & 66 & 38 \\
\hline 5 & M & 41 & 0 & Chest Compression Trauma & Hematopneumothorax, Flail Chest, Cardiac Tamponade & Close & 66 & 25 \\
\hline 6 & $\mathrm{~F}$ & 55 & 0 & Chest Ab. Sharp Trauma & $\begin{array}{c}\text { Chest Abdominal Penetration Injury, Abdominal Aorta Rupture Lung } \\
\text { Lobe Penetration Injury }\end{array}$ & Open & 75 & 35 \\
\hline 7 & M & 34 & 0 & Falling Polytrauma & Hematopneumothorax, Lung Rupture, Basal Fracture, Spleen Rupture & Close & 66 & 17 \\
\hline 8 & M & 48 & 0 & Traffic Accident & $\begin{array}{l}\text { Cranial Contusion and Laceration, Hematopneumothorax, Pelvic } \\
\text { Fracture }\end{array}$ & Close & 66 & 55 \\
\hline 9 & M & 28 & 1 & Chest Ab. Sharp Trauma & Cardiac Rupture, Cardiac Tamponade, Hematopneumothorax & Open & 66 & 30 \\
\hline 10 & M & 21 & 2 & Chest Compression Trauma & Hematopneumothorax, Spleen Rupture, diaphragmatic hernia & Close & 59 & 5 \\
\hline 11 & M & 33 & 0 & Traffic Accident & $\begin{array}{l}\text { Hematopneumothorax, Cranial Contusion and Laceration, Multiple } \\
\text { Fracture }\end{array}$ & Close & 66 & 25 \\
\hline 12 & $\mathrm{M}$ & 45 & 1 & Traffic Accident & Cardiac Rupture, Cardiac Tamponade, Hematopneumothorax & Close & 66 & 25 \\
\hline 13 & $\mathrm{~F}$ & 56 & 1 & Suicide & Hematopneumothorax, Cranial Contusion and Laceration, Hepatorrhexis & Close & 75 & 15 \\
\hline 14 & M & 22 & 2 & Chest Ab. Poly-sharp Trauma & Cardiac Rupture, Cardiac Tamponade, Hematopneumothorax & Open & 66 & 15 \\
\hline 15 & M & 17 & 0 & Chest Sharp Trauma & Aorta Rupture, Hematopneumothorax, Lung Rupture & Open & 75 & 13 \\
\hline 16 & M & 12 & 0 & Traffic Accident & $\begin{array}{l}\text { Hematopneumothorax, Cranial Contusion and Laceration, Multiple } \\
\text { Fracture }\end{array}$ & Close & 66 & 35 \\
\hline 17 & M & 9 & 0 & Traffic Accident & $\begin{array}{l}\text { Hematopneumothorax, Cranial Contusion and Laceration, Multiple } \\
\text { Fracture }\end{array}$ & Close & 66 & 35 \\
\hline 18 & $\mathrm{~F}$ & 32 & 1 & Falling Polytrauma & $\begin{array}{l}\text { Cranial Contusion and Laceration, Hematopneumothorax, Pelvic } \\
\text { Fracture }\end{array}$ & Close & 66 & 20 \\
\hline 19 & M & 27 & 2 & Traffic Accident & Hematopneumothorax, Frostbite & Close & 29 & 15 \\
\hline 20 & $\mathrm{M}$ & 55 & 1 & Traffic Accident & $\begin{array}{l}\text { Cranial Contusion and Laceration, Cerebral Hemorrhage, Cervical } \\
\text { Vertebrae Fracture }\end{array}$ & Close & 64 & 25 \\
\hline 21 & M & 66 & 1 & Traffic Accident & Cerebral Hemorrhage, Hematopneumothorax, Hemoperitoneum & Close & 48 & 20 \\
\hline 22 & $\mathrm{~F}$ & 55 & 1 & Suicide & Hematopneumothorax, Hemoperitoneum, Cerebral Hemorrhage & Close & 66 & 20 \\
\hline 23 & $\mathrm{M}$ & 33 & 1 & Falling Polytrauma & $\begin{array}{l}\text { Hematopneumothorax, Liver Spleen Kidney Laceration, Thoracic } \\
\text { Vertebrae Fracture }\end{array}$ & Close & 57 & 20 \\
\hline 24 & M & 29 & 1 & Traffic Accident & Hematopneumothorax, Spleen Rupture, Pelvic Fracture & Close & 57 & 20 \\
\hline 25 & M & 19 & 1 & Sharp Trauma & Cardiac Rupture, Cardiac Tamponade, Hematopneumothorax & Open & 59 & 15 \\
\hline 26 & M & 36 & 1 & Electrocution & Cerebral Hemorrhage, Pelvic Fracture, Lumbar Vertebrae Fracture & Close & 34 & 18 \\
\hline 27 & $\mathrm{~F}$ & 66 & 1 & Suicide & Jugular Vein Rupture, Tracheal Rupture, Thyroid Rupture & Open & 34 & 18 \\
\hline 28 & $\mathrm{~F}$ & 67 & 2 & Traffic Accident & Hematopneumothorax, Cerebral Hemorrhage, Spleen Kidney Rupture & Close & 57 & 30 \\
\hline 29 & M & 44 & 0 & Falling Object Blunt Trauma & Left Chest Penetration Injury, Lung Rupture, Aorta Pectoralis Rupture & Open & 75 & 15 \\
\hline 30 & $\mathrm{M}$ & 28 & 0 & Chest Sharp Trauma & $\begin{array}{c}\text { Chest Penetration Injury, Right Hilum Detachment, } \\
\text { Hematopneumothorax }\end{array}$ & Open & 66 & 15 \\
\hline 31 & M & 37 & 0 & $\begin{array}{l}\text { Chest Ab. Compression } \\
\text { Trauma }\end{array}$ & Hematopneumothorax, Hepatorrhexis, Spleen Rupture & Close & 57 & 20 \\
\hline 32 & M & 41 & 0 & $\begin{array}{l}\text { Chest Ab. Compression } \\
\text { Trauma }\end{array}$ & Hematopneumothorax, Spleen Rupture, Kidney Rupture & Close & 50 & 15 \\
\hline 33 & $\mathrm{~F}$ & 39 & 1 & $\begin{array}{l}\text { Cranial Chest Ab. } \\
\text { Compression Trauma }\end{array}$ & Cerebral Hemorrhage, Hematopneumothorax, Hemoperitoneum & Close & 57 & 10 \\
\hline 34 & $\mathrm{~F}$ & 65 & 0 & Falling Injury & Cerebral Hemorrhage, Hematopneumothorax, Hemoperitoneum & Close & 75 & 30 \\
\hline 35 & M & 28 & 2 & Sharp Trauma & Cardiac Rupture, Cardiac Tamponade, Hematopneumothorax & Open & 66 & 19 \\
\hline 36 & M & 33 & 0 & $\begin{array}{l}\text { Cranial Chest Ab. } \\
\text { Compression Trauma }\end{array}$ & Hematopneumothorax, Lung Rupture, Basal Fracture, Spleen Rupture & Close & 57 & 17 \\
\hline 37 & M & 55 & 0 & $\begin{array}{l}\text { Cranial Chest Ab. } \\
\text { Compression Trauma }\end{array}$ & Hematopneumothorax, Lung Rupture, Hepatorrhexis, Spleen Rupture & Close & 57 & 25 \\
\hline 38 & M & 41 & 0 & $\begin{array}{l}\text { Cranial Chest Ab. } \\
\text { Compression Trauma }\end{array}$ & Hematopneumothorax, Lung Rupture, Spleen Rupture, Kidney Rupture & Close & 57 & 10 \\
\hline 39 & M & 69 & 1 & Traffic Accident & Cerebral Hemorrhage, Basal Fracture, Hematopneumothorax & Close & 57 & 30 \\
\hline 40 & M & 38 & 1 & Electrocution Falling Trauma & Hematopneumothorax, Thoracic Vertebrae Fracture, Pelvic Fracture & Close & 34 & 10 \\
\hline
\end{tabular}


Table 2. Age Comparison in 3 Groups.

\begin{tabular}{|c|c|c|c|}
\hline Group & Age (yr) & $\boldsymbol{F}$ Value & P Value \\
\hline Complete Recovery & $32.67 \pm 17.24$ & 1.898 & 0.164 \\
\cline { 1 - 2 } Re-established Circulation Mortality & $44.40 \pm 15.75$ & & \\
\cline { 1 - 2 } Non-survivor & $35.32 \pm 14.89$ & & \\
\hline
\end{tabular}

Table 3. NISS Comparison in 3 Groups.

\begin{tabular}{|c|c|c|c|}
\hline Group & Age (yr) & F Value & P Value \\
\hline Complete Recovery & $56.00 \pm 5.62$ & 2.824 & 0.072 \\
\cline { 1 - 2 } Re-established Circulation Mortality & $56.00 \pm 3.35$ & & \\
\cline { 1 - 2 } Non-survivor & $64.21 \pm 1.80$ & & \\
\hline
\end{tabular}

Table 4. Time from Admission to OCCPR.

\begin{tabular}{|c|c|c|c|}
\hline Group & Age (yr) & $\boldsymbol{F}$ Value & P Value \\
\hline Complete Recovery & $14.50 \pm 9.83$ & 4.102 & 0.025 \\
\cline { 1 - 2 } Re-established Circulation Mortality & $19.73 \pm 6.02$ & & \\
\cline { 1 - 2 } Non-survivor & $26.58 \pm 12.18$ & & \\
\hline
\end{tabular}

Table 5. Multiple Comparison of the Time Elapsed from Admission to OCCPR.

\begin{tabular}{|c|c|c|c|}
\hline Group & $\begin{array}{c}\text { Complete } \\
\text { Recovery }\end{array}$ & $\begin{array}{c}\text { Re-established } \\
\text { Circulation Mortality }\end{array}$ & Non-Survivor \\
\hline Complete Recovery & - & 0.283 & 0.014 \\
\hline $\begin{array}{c}\text { Re-established } \\
\text { Circulation Mortality }\end{array}$ & - & - & 0.054 \\
\hline Non-survivor & - & - & - \\
\hline
\end{tabular}

recovery group was $14.50 \pm 9.83$ minutes, the Re-established Circulation Mortality group was $19.73 \pm 6.02$ minutes, the non-survivor group was $26.58 \pm 12.18$ minutes, which shows statistical significance $(P=0.025)$ as seen in Table 4. Further multiple comparison shows the time elapsed for complete recovery group and re-established circulation mortality group shows statistical significance $(p=0.014)$ as seen in Table 5 [6-11].

\section{Discussion}

OCCPR differ from the traditional cardiopulmonary resuscitation in the method of compression, which is done directly to the heart using one hand, therefore resulting in a more effective stroke volume. OCCPR has been a viable method of resuscitation for more than 100 years and the very first case of OCCPR was performed by Dr. Paul Niehans in 1880 , on a patient who underwent cardiac arrest during an operation.

Studies have shown that TCPA especially thoracic trauma is the leading cause of death in patients, the success rate of the traditional method of CPR is almost $0 \%$. The patient is often presented with incomplete or damaged thoracic support, the cause of death is not trauma to the heart or underlying cause relating to the heart but purely mechanical abnormality which inhibits respiratory and circulatory system which leads to acute respiratory and circulatory arrest. The only possible method of performing $\mathrm{CPR}$ on a collapsed thoracic cavity is to perform OCCPR. Firstly, OCCPR does not rely on the completeness of the thoracic cavity or the intrathoracic abdominal pressure, which is direct compression to the heart, providing good volume stroke and perfusion to the vital organs, such as the brain [12]. In the Dog Resuscitation model done by Byme et al, it was able to obtain approximately $100 \%$ of cerebral blood flow and at the same time maintain an almost normal cerebral cortex and cerebellum perfusion [13]. Secondly while performing OCCPR, surgeons can directly treat lethal comorbidities such as hematopneumothorax, cardiac tamponade or ruptures of major arteries, which can increase overall success rate of resuscitation, if the surgeon is trained, resuscitation can be done with minimal time needed.

Research shows there is a close relationship between survival rate and the length of cerebral ischemia, $p=0.014$. A 2014 ITLS done by John E. Campbell shows perceptive internvention and differentiation can save lives. Therefore, we have proposed the concept of early implementation of OCCPR. It has 3 contents which include the identification and information collection of patients in need of OCCPR, then making the information available to trauma teams; After obtaining relevant information such as type of trauma, consciousness, respiratory arrest or abnormal breathing, the OCCPR team can participate in the on-sight treatment; the resuscitation performed on-sight, or in an ambulance was carried out by professional personnel, this can shorten valuable time needed by $5-10$ minutes $[14,15]$.

An early implementation of OCCPR on patients with chest or abdominal trauma undergoing cardiac arrest can provide three reliable solutions. First, OCCPR provides the patient with an early effective blood circulation. Second, while performing OCCPR, possible fatal injuries to the heart can also be corrected using Phase I treatment, the injuries may include cardiac tamponade, cardiac rupture as well as tension pneumothorax; Keiko was able to successfully resuscitate a patient by correcting cardiac tamponade using Phase I treatment while performing OCCPR [16]. Third, OCCPR performed on sight or as early as possible can further lower the risk of irreversible damage done by cerebral ischemia and improve the success rate of cardiopulmonary resuscitation.

In our experience, most patients and their family members were able to accept the method of OCCPR, which were especially evident in younger patients [17]. This makes it possible to implement OCCPR at the right moment on patients with cardiac arrest.

In a study of 38 cases of blunt chest/abdominal trauma, Fialka $e t$ al. had implemented OCCPR to patients with cardiac arrest that lasted no more than 20 minutes, which was proven that there is a correlation between the severity of the trauma and the success rate of OCCPR. The earlier the implementation of OCCPR, the higher success rate [18]. Matsumoto et al believes that guidance from an experienced physician in an early implementation of OCCPR to blunt trauma related cardiac arrest is key to increasing the survival rate of the patients [19].

Presently, researches done domestically and abroad shows that OCCPR was worthy of further promotion and standardization, onsight or early implementation in an emergency scenario was the key to increasing survival rate; trauma related cardiac arrest patients and patients whose circulation is re-established and resuscitated by OCCPR shows a higher rate of complete recovery, this is followed by patients whose OCCPR was carried out in ER setting, and lastly OCCPR done at a surgical consultation [18-22].

Time: Following a procedure in a timely manner is a difficult problem to deal with [15]. Presently, almost all around the world, the ER team in most trauma centers are composed of individuals inexperienced with OCCPR, they can only transfer patients to hospitals, but it is unfortunate to say that occasionally, the ER doctors at such hospitals are also inexperienced with OCCPR and can only consult in the doctors from the thoracic surgery department, these series of events often lead to missing the most opportune moment to perform OCCPR, resulting in a less than desirable success rate of cardiac resuscitation. Time is often wasted in the following: 1) The Pre-hospital operator cannot determine whether the injured individual needed OCCPR implemented on sight, 2) Pre-hospital doctors do not have the ability 

40 cases

to perform OCCPR, 3) after transferring to the ER, doctors on duty are not equipped with the ability to carry out OCCPR, and therefore consults in another department, thus, time for performing resuscitation is wasted, rendering the success rate of OCCPR undesirable.

In the 40 cases presented, 15 cases had OCCPR performed on sight, 25 cases performed at ER by doctors on duty, time elapsed from receiving distress call to implementing OCCPR is $5.83 \sim 26.58$ minutes, drastically lower than any other OCCPR reported. Looking at the collected data, the prognosis of the patients with thoracic and abdominal trauma is closely relative to the timely intervention of OCCPR as well as the severity of the injury, therefore, it can be said that the earlier the OCCPR the greater chances of complete recovery, this is especially so for thoracic cardiac trauma individuals.

Open trauma and closed trauma: Within the 40 cases of TCPA, 8 cases were open trauma, 32 were close trauma, of the 6 cases that made recovery, 3 were open trauma, 3 were close trauma. There were two reasons for the significant difference in survival rate: firstly, open trauma often is seen as an individual problem and treatment plans can be made according to the location of the wound and precisely locate the underlying fatality factors; secondly the risk of pericardial tamponade or tension pneumothorax in an open trauma is low. Close trauma are often present the difficulty of locating the underlying lesions.

Location Normally OCCPR should be performed in an ambulance or inside an operating room, which can greatly shorten the intervention time of OCCPR, and increase the success rate of resuscitation. This is especially vital to patient with severe thoracic cardiac puncture trauma undergoing cardiac and respiratory arrest, OCCPR as well as effective hemostasis performed in an ambulance as a phase I treatment can lead to an increase success rate of phase II surgery [15].

With a competent and highly trained team and an advanced multifunctional medical transportation such as an ambulance or a helicopter, life-saving treatments for the critically wounded is easily carried out on sight, not only is mortality and disability of the wounded lowered, but the enhancement of treatment standard is raised. We believe under the right circumstances; trauma center medical staff should be actively involved in any pre-hospital emergency.

The technique for OCCPR is not all that difficult, with the right training and mastering of the indications for OCCPR, as well as the correct method of operation and the ability to deal with Phase I treatments, OCCPR in the field of emergency department is not difficult to grasp. We believe OCCPR deserves further promotion and standardization; early implementation of OCCPR is vital in increasing the survival rate of the wounded.

\section{References}

1. Pape HC, Remmers D, Rice J, Ebisch M, Krettek C, et al. (2000)Appraisal of early evaluation of blunt chest trauma: development of a standardized scoring system for initial clinical decision making. J Trauma 49: 496-504.

2. Luce JM, Rizk GB, Rivers EP (1992) Use of open chest cardiopulmonary resuscitation after failure of standard closed chest cardiopulmonary resuscitation: illustrative cases. Resuscitation 24:61-71

3. Tisherman SA, Vandevelde K, Safar P, Morioka T, Obrist W, et al. (1997) Future directions for resuscitation research. V. Ultra-advanced life support. Resuscitation 34: 281-293.[Crossref]

4. Delguercio LR, Feins NR, Cohn JD, Coomaraswamy RP, Wollman SB, et al. (1965) Comparison of blood flow during external and internal cardiac massage in man. Circulation 1: 171-180.[Crossref]

5. Carreia JC, Phair I (2000) Physiological variables during open-chest cardiopulmonary resuscitation: results form a small series. J Accid Emerg Med 17: 201-204.
6. Manzur FV, Varon J, Fromm R, Baskett P (2002)Moritz Schiff and the history of openchest cardiac massage. Resuscitation 53: 3-5.

7. Zesas DG(1903) Zurfrage der HermassagebeimChloroformkollaps. Cantralblatt fur Chirugie 17: 588-589.

8. Jackson RE, Freeman SB (1983) Hemodynamics of cardiac massage. Emerg Med Clin North Am 1: 501-513.[Crossref]

9. Kern KB, Sanders AB, Badylak SF, Janas W, Carter AB, et al. (1987)Long-term survival with open-chest cardiac massage after ineffective closed-chest compression in a canine preparation. Circulation 75: 498-503.

10. Martin GB, Carden DL, Nowak RM, Tomlanovich MC (1985) Central venous and mixed venous oxygen saturation: comparison during canine open-chest cardiopulmonary resuscitation. Am J Emerg Med 3: 495-497.

11. Martin GB, Carden DL, Nowak RM, Tomlanovich MC (1985) Comparison if central venous and arterial $\mathrm{pH}$ and $\mathrm{pCO}_{2}$ during open-chest cardiopulmonary resuscitation in the canine model. Ann Emerg Med 14: 529-533.

12. Bircher N, Safar P (1981) Comparison of standard and "new" closed-chest CPR and open-chest CPR in dogs. Crit Care Med 9: 384-385.[Crossref]

13. Byrne D, Pass HI, Neely WA, Turner MD, Crawford FA Jr (1980) External versus internal cardiac massage in normal and chronically ischemic dogs. Am Surg 46: 657662.[Crossref]

14. Tisherman SA, Vandevelde K, Safar P(1997) Future directions for resuscitation research Ultra-advanced life support. Resuscitation 34:281-293.

15. Mayr NP, Martin K, Kurz J, Tassani P (2011) Monitoring of cerebral oxygen saturation during closed-chest and open-chest CPR. Resuscitation 82: 635-636.[Crossref]

16. Keiko T, Yanagawa Y, Isoda S (2012) A successful treatment of Cardiac Tamponade due to an aortic dissection using open-chest massage. Am J Emerg Med 30: 634.e1-2.

17. Sakamoto T, Saitoh D, Kaneko N, Kawakami M, Okada Y, et al. (2000) Is emergency open chest cardiopulmonary resuscitation accepted by patients' families? Resuscitation 47: 281-286.

18. Fialka C, Sebök C, Kemetzhofer P, Kwasny O, Sterz F, et al. (2004) Open-chest cardiopulmonary resuscitation after cardiac arrest in cases of blunt chest or abdominal trauma: a consecutive series of 38 cases. $J$ Trauma 57: 809-814.[Crossref]

19. Matsumoto H, Mashiko K, Hara Y, Kutsukata N, Sakamoto Y, et al. (2009)Role of resuscitative emergency field thoracotomy in the Japanese helicopter emergency medical service system. Resuscitation 80:1270-1274.

20. Hachimi-Idrissi S, Leeman J, Hubloue Y, Huyghens L, Corne L, et al. (1997)Open chest cardiopulmonary resuscitation in out-of-hospital cardiac arrest. Resuscitation 35: 151-156.

21. Takino M, Okada Y (1993) The optimum timing of resuscitative thoracotomy for nontraumatic out-of-hospital cardiac arrest. Resuscitation 26: 69-74.

22. Liu Wen-hai, Li ting, Yan Bo (2007) Emergency Open Chest CPR for Chest Injuny Chinese Journal of Hemorheology 17: 433-434.

Copyright: (C2017 Liu WH. This is an open-access article distributed under the terms of the Creative Commons Attribution License, which permits unrestricted use, distribution, and reproduction in any medium, provided the original author and source are credited. 